\title{
Biomateriales tissue engineering and treatment of tooth with apex unripe: revascularization
}

\begin{abstract}
The pulp damage due to trauma or caries in teeth with immature apex may lead to loss of vitality and the arrest of root development, resulting in short roots with thin walls and increased risk of fracture thus hindering the treatment which either ducts. Revascularization is a regenerative treatment an alternative biological approach to treat immature teeth with necrotic pulp caries or trauma, unlike apexification and techniques positing apical artificial barriers, allows the continuation of root development. All this monopolized by the use of natural bio-stimulants, such as stem cells suggests that the pulp regeneration is a reality.
\end{abstract}

Keywords: revascularization, maturogénesis, apexification, revitalization, biomaterials, MTA, calcium hixroxide, PRGF
Volume 9 Issue 6 - 2018

\author{
Marcos Moradas Estrada,' Beatriz Álvarez \\ López $^{2}$ \\ 'Department of Conservative Dentistry, University of Oviedo, \\ Spain \\ ${ }^{2}$ Odontologist, Primary Health Care Area I of the Health \\ Service of the Principality of Asturias, Spain
}

\author{
Correspondence: Marcos Moradas Estrada, Department of \\ Conservative Dentistry, University of Oviedo, Spain, \\ Emailmarcosmards@gmail.com \\ Received: December II, 2017 | Published: November 19, \\ 2018
}

\section{Introduction}

Traumatic tooth injuries can lead to myriad forms of dental pathology: sprains, fractures uncomplicated coronary pulp, pulpal coronary fractures, root fractures, resorptions, avulsions, among others. In any case, the treatment plan will get sealing the passageway so endodontic therapeutic seek essential objective complete obturation of the root canal space. An essential factor to achieve this goal will be a good apical stop. This will allow proper condensation of root canal that leads to success. ${ }^{1-5}$ However, should not be forgotten as when immature teeth have suffered trauma resulting pulp necrosis with loss of vitality, this leads to developmental arrest of these teeth; It is making the conduit present a parallel or divergent walls in the apical third and the apical stop does not occur. ${ }^{6}$ This circumstance leads to the impossibility of filling material remains delimited pulp space. ${ }^{7}$ The quasi total cessation of root development caused by trauma or by a pulpal presents an endodontic challenge and restorer, pus apical divergent form almost impossible clean and shape the canal, and especially, seal it correctly. Therefore in the last decade it has sought the method of getting dentine apposition through phenomena then described as maturogénesis and subsequent revascularization. ${ }^{4}$ The regenerative revascularization is an alternative treatment based on treating immature teeth with necrotic pulp or caries caused by trauma, which allows root development and hard tissue deposition in the duct. It is based on the concept as vital stem cells present in the pulp chamber can survive pulp necrosis offering ability to differentiate into odontoblasts side and thus contribute to the formation of root tissue., ${ }^{4,6,10}$ In 1966 Frank AL published a clinical technique that was aimed at inducing apical closure. Using repeatedly intracanal medication with calcium hydroxide during 3 - 6 months showed that it was not only possible repair of the apical but also induction apical closure with calcified tissue. ${ }^{8,9}$ Nygard Ostby, in the sixties, showed that could be promoted vascularization in new cases of teeth with pulp necrosis and periapical lesions through the induction of a clot in the apical third of the root canal disinfected, exceeding a file before I seal it. Already in 2001, ${ }^{10,11}$ Iwaya described revascularization in cases with necrotic pulp and chronic apical abscess, showing radiographically, after 30 days, a thickening of the walls of the root canal with mineralized tissue, a positive response to sensibility and complete root formation after 30 months. While Banchs and Trope, based on the treatment of immature premolar with open apex and extensive injury, noted that it was possible pulpal tissue regeneration in a necrotic tooth infected with apical periodontitis. ${ }^{9,12}$ Although the term revascularization is debatable since it implies the presence of blood flow, and Lenzi Trope suggested the term revitalization thus describe Nonspecific vital tissue forming in the root canal. In 2008, Hagreaves et al, They coined the term maturogénsis for continuous root development, in contrast to apoxogénesis, describing how apical closure. We can say that the conditions of universal acceptance for these procedures are being considered and have yet to result by the American Association of Endodontics.

\section{Materials and methods}

For the preparation of this review paper published evidence in major industry magazines were consulted, using a search engine referral as PubMed, resulting in more than 935 articles, which after applying different criteria of inclusion and exclusion, such as publication no more than 15 years, impact rate 1 to 2 and keywords above, for a total of 69 articles, of the 31 which were excluded for methodological errors, technical and/or statistical, thereby utilizing only 38 items that match the type of systematic reviews, clinical trials and clinical cases.

\section{Other methods, techniques and materials in common use $^{13-16}$}

Revascularization therapy has become an alternative in necrotic immature parts in the field of endodontics. The practice of revascularization is performed by endodontists in young patients represent a challenge for the inexperienced operator behavior management leading to poor patient behavior and bad treatment. Apexification with calcium hydroxide, gives results in an acceptable treatment, but after a while the treated tooth is more fragile, however, revascularization to present a thickening of the walls of the root, leads 
to a prognosis long term apexification greater than calcium hydroxide. Recent advances and promising future based techniques exploit rich plasma growth factor, stem cells and all its derivations allow us to treatments such as revascularization, which helps improve the conditions of necrotic immature parts helping tissues pieces continue their development and that parts are not susceptible to fractures. Various techniques and materials procedures, some historic, for the treatment of immature apex in permanent tooth, although few have been shown with positive evidence medium/long term, plus some difficulty as far as handling is concerned. Elif TB, defined dental trauma as the key factor precipitating a root canal on a tooth with immature apex, and speaks of its most prevalent in anterior teeth in young age groups and adolescents, resulting from accidents.

\section{Biological considerations: biomateriales ${ }^{17-21}$}

Regeneration procedures in endodontics are based, biologically, in restoring function pulp damaged by stimulating existing stem or stem cells in the root canal and / or the introduction and stimulation of new stem cells under conditions favorable for differentiation, allowing replace damaged root structures and complex cells dentine - pulp. This objective is sought through endodontic debridement procedures and a combination of drugs that reduce infection to promote repair. Regeneration as such, however, arises through a histological observation and can not be determined radiographically. The nature of the tissue formed in the canal space in immature human permanent teeth with apical periodontitis is speculative because the presence of histological studies is almost incidental. In 2012, Shimizu made the revascularization procedure on a maxillary central incisor; three weeks and half extracted part due to fracture to value for histological and immunohistochemical technique, finding loose connective tissue with few collagen fibers within the conduit absence of fusiform mesenchymal cells in the duct and periapex; certain amount of blood vessels and absence of nerve fibers. The loose tissue was similar to immature tissue pulp.

\section{Skip medium / long term treatment based pulp revascularization ${ }^{21,23}$}

The main advantages reported revascularization treatments are:

a. Regeneration of tissue in the root canal of the patient's own blood cells avoids the possibility of immune rejection and the potential transmission of pathogens from the substitution of the pulp with a construct generated by tissue engineering.

b. drugs required to disinfect the root canal can be easily obtained and can be introduced through endodontic instruments convencionales. ${ }^{16}$

c. Radiographic evidence of continued root development and strengthening the root as a result of strengthening the dentine walls in several clinical cases. While the disadvantages reported are:

d. Clinical long-term results are still controversial with potential complications, such as lack of significant continuity of root development, lack of apical closure or calcification of the duct.

e. Lack of whether the nature of the tissue formed in the conduit wall is actually composed of dentin.

f. Possible complications such as coronary pigmentation, development of resistant bacterial strains and intracanal medication allergic to using the paste triantibiótica reactions.

g. There is no universal protocol described in the literature.

h. they have been recommended follow-up periods ranging from 6 to 36 months to five years, which in many cases is little factible., , $^{1,7,7,8,12}$

\section{Technical and systematic as possible in revascularisations: ${ }^{23,25-28}$}

Protocols proposed in the literature for revascularization are varied, and although there is no universal protocol, most of the literature is based on the following principles:

1. Chemical Disinfection conduit without performing instrumentation.

2. Suitable environment for a scaffold that supports tissue growth.

3. Hermetically sealed to prevent the ingress of bacteria to the root canal.

Different protocols revascularization shown in the literature have as common ground for the first session local anesthesia, absolute isolation, access and copious irrigation with $20 \mathrm{~mL}$ of sodium hypochlorite, preferably at a low concentration to minimize cytotoxicity on stem cells of the apical tissues; after drying duct an antibacterial agent is placed. Perhaps most associated with revascularization is the triantibiótica paste (ciprofloxacin, metronidazole and minocycline) mixed with distilled water and introduced a lentulo in the duct. It should be noted that minocycline, like all tetracycline, be pigmented to tooth, which can be used phosphoric acid 35\% for 20 seconds, placing adhesive and fotocurarlo for 30 seconds to protect the labial surface of the pulp chamber Contact with triantibiótica or paste may opt for cefaclor to replace minocycline in triantibiótica pasta. The second option as undependable intracanal antibacterial agent is calcium hydroxide, which is effective at concentrations that do not induce cytotoxicity of stem cells and is readily available. 1: a homogeneous paste of $\mathrm{Ca}(\mathrm{OH})_{2}$ mixed with sterile water in proportion 3 is prepared. Once medicated sealed with Cavit 3-4mm, followed by MRI or glass ionomer and thus left for 3-4 weeks. For the second session also there are commonalities in literature reports, these are anesthesia without vasoconstrictor to prevent suppress bleeding, the complete isolation and removal of the antibacterial agent by heavy and slow irrigation with $20 \mathrm{~mL}$ of $17 \%$ EDTA or $\mathrm{NaOCl}$ or saline, to subsequently dry with paper points. From this point there are several phases indicated by the protocol that the case, so that known as "regenerative endodontic" proposes removing the patient from 5 to $20 \mathrm{~mL}$ of blood for plasma centrifugation platelet rich, introduced into the line and wait to form the clot. The other aspect, perhaps more widespread, is to induce bleeding exceeding the instruments $2 \mathrm{~mm}$ beyond the working length to form a clot occupying up to 2 to $3 \mathrm{~mm}$ below the cementoenamel junction togetherness. Once this is accomplished, a barrier material as MTA, wet cotton swab is placed thereon; although it has also been proposed an enriched calcio ${ }^{29}$ mixture and subsequently a temporary restorative material Cavit by a period ranging from three days to four weeks after a final restoration material. There is also a protocol revascularization on a date by irrigation with $10 \mathrm{~mL}$ of $6 \%$ $\mathrm{NaOCl}$, sterile saline and $10 \mathrm{~mL}$ chlorhexidine gluconate $2 \%$ for 5 minutes without performing instrumentation; conduit dried, MTA is introduced and a layer thermoplasticized gutta percha temporary to 
avoid washing the MTA; recording with phosphoric acid, rinsed with saline solution and dried, gutta percha is removed and resin is placed.

\section{Tissue engineered future for treating pulp necrosis: biomaterial $100 \%{ }^{29,30}$}

The principles of regenerative medicine can be applied to endodontics based on tissue engineering. Regenerative endodontic research includes adult stem cells, growth factors, tissue culture, and tissue engineering materials. Often these disciplines are combined rather than used individually to create regenerative therapies. three necessary components are recognized to achieve revascularization, which are:

1. Stem cells capable of forming hard tissue present in the pulp stump and periapical tissues.

2. Signal molecules necessary for stimulation, proliferation and differentiation to be derived from blood.

3. A scaffold or hardware that can support cell growth and differentiation, whose role would be carried out by the clot.

Protocols for the use of a blood clot state that it can act as a scaffold for revascularization of infected immature teeth, as suggested by many researchers. Induction of hemorrhage disinfected conduit is based on the principle that the clot, besides serving as a support, can provide factors that stimulate cell growth and differentiation of undifferentiated cells or stem cells into odontoblasts.

\section{Stem cells as dental materials $\mathbf{s}^{30,31}$}

Also identified as stem cells or stem cells are the natural units from which can be distinguished all other existing in the body. The development of techniques for isolation, culture, expansion and differentiation has not only advanced the understanding of biology, but also to evaluate the extent of their use in medicine regenerative. ${ }^{9}$ In the mouth there is a huge reservoir of mesenchymal stem cells, whose potential as adults multidiferenciación forming units guarantees other with osteodontogénico character, adipogenic and neurogénico. ${ }^{10^{-12}}$ González et al, 13 who have devoted special attention to the study of the main mother in said cavity, cells have identified four groups: pulp deciduous teeth (SHED), pulp of permanent teeth, periodontal space and the buccal mucosa. Meanwhile, Huang et al. ${ }^{14}$ agree with the points made by previous authors and claim to have found 2 new groups of stem cells in the cavity: the apical papilla (SCAP) and the dental follicle. The SCAP have been used with surprising in endodontic regeneration of immature teeth with pulp necrosis results. This method includes the root canal disinfection and induction of intracanal bleeding, which introduces stem cells originating apical papilla to produce a blood clot and form a matrix sterile tissue, the new cells capable of growth are provided and restore the vitality pulp. Revascularization process is innovative and future can successfully replace treatments such as apexification, as already stated in some reports on the subject. Well, a big question the survival of these cells as hostile as those observed in the periapical inflammation means, although it is presumed that it could be possible by the low density of blood vessels in that region. In this regard, japoneses17 authors have shown that hypoxic environments increase the proliferation and angiogenic potential of stem cells.

\section{Growth ${ }^{31}$}

They are proteins that bind to cell receptors and function as signals for promoting cell proliferation and differentiation. Among the most common factors in the regeneration process of the dentin-pulp complex projecting the transforming growth factor beta (TGF- $\beta$ ) and bone morphogenetic protein (BMP), although recent studies have shown that dentin acts as a reservoir of those factors, which when released by cauterizing agents, acids or carious lesions induced demineralisation once, have a key role in the formation of tertiary dentin.

\section{Matrix growth 29,3}

To regenerate the tissues within the root canal, the presence of a growth matrix that promotes a favorable environment for the organization, proliferation, differentiation and cell regeneration is necessary. For these purposes are recommended the blood clot and platelet rich plasma (PRP), both already used for this purpose

\section{Discussion}

\section{Revascularization/revitalization can be defined as a treatment}

allowing regenerative restoring development and strengthening of the root structure, because it has the potential to create hard tissue that has the ability to seal the apex, increasing the thickness of the dentinal walls and root length. ${ }^{31}$ The mechanisms involved in this procedure are stem cells. ${ }^{32}$ Various authors state that the cells responsible for the formation of new hard tissue are those located in the apical papilla. They have survived the infectious process and subsequent debridement and disinfection. Huang proposed the possibility that stem and progenitor cells of the periodontal ligament may be present when the apical irritation is induced and suspected mineralized tissue is formed from these cells ${ }^{33-35}$ Studies such as Becerra et al. show that after revascularization/revitalization fibrous connective tissue similar to that found in the periodontal ligament is formed, and also similar to cement and bone tissue, which is consistent with proposed by Huang. ${ }^{36}$ The placement of matrices within the conduit has been controversial among various authors. Thibodeau et al. in 2007 concluded that there is no evidence statistically significant as the benefit of using a solution of collagen for revascularization process matrix, however the formation of a clot within the canal space and optimal disinfection if they improve the prognosis treatment. ${ }^{37}$ Yamauchi et al. They set out that using a matrix of insoluble collagen in combination with the clot, allowing the cells to proliferate and migrate, since the matrix is not reabsorbed as fast; also they conclude that it is likely that results obtained by Thibodeau et al. occurred by the use of a soluble collagen matrix failed to provide stability to the clot. ${ }^{37}$ Many cases exist in the literature have used the MTA as the bioactive material of choice to promote formation of new mineralized tissue. In the first case overextension MTA radiographically evident apically, similar was reported by Petrino et al in one case report, enunciate ideally should be placed between 1-2mm below the cementoenamel MTA limit as this allows greater root development. ${ }^{38}$ white MTA was used In both cases documented in this article, however pigmentation was seen in the patients teeth. Currently there bioceramic materials such as calcium or enriched mixture (CEM) that produce pigmentations or may recommend the use of protocol Reynolds. 


\section{Acknowledgements}

None.

\section{Conflict of interest}

The authors declare that there is no conflict of interest.

\section{References}

1. González VM, Madrid KC, Amador EA, et al. Revascularization in permanent teeth with immature apex and pulpal necrosis: Bibliographic review. ADM. 2014;71(3):110-114.

2. Brizuela C, Saint Jean N. Tissue engineering and biomaterials in the treatment of the tooth with immature application: revascularization. Rev Soc Endod Chile. 2011;24:32-37.

3. Palomino M, Mendiola C, Velásquez Z. Revascularization New alternative for the treatment of immature teeth with non vital pulp. Rev Estomatol Hered. 2011.

4. Cvek M. Prognosis of luxated non-vital maxillary incisors treated with calcium hydroxide and filled with gutta-percha. A retrospective clinical study. Endod Dent Traumatol. 1992;8(2):45-55.

5. Cehreli Z, Sesgi S, Uysal S, Turgut M. MTA apical plugs in the treatment of traumatized immature teeth with large periapical lesions. Dent Traumatol. 2011;27(1):59-62.

6. Salgado Sousa T, Andrade Deonizio M, Batista A, et al. Endodontic Regeneration: Is There a Protocol?. 2013;22(63).

7. Law A. Outcomes of regenerative endodontic procedures. Dent Clin North Am. 2012;56(3):627-637.

8. Rendón J, Jiménez CP, Urego PA. Stem cells in dentistry. Rev CES Odontol. 2011;24(1):51-58.

9. Ardier Montalvo JE. Cellular therapies based on the use of stem cells. Avan Biomed. 2013; Supl 1:51-52.

10. Kim R, Mehrazarin S, Kang MK. Therapeutic potential of mesenchymal stem cells for oral and systemic diseases. Dent Clin North Am. 2012;56(3):651-675.

11. Nosrat A, Fouad A. Pulp regeneration in previously infected root canal space. Endodontics Topics. 2013;28(1):24-37.

12. Betancourt Gamboa K, Barciela Calderón J, Guerra Menéndez J, et al. Use of stem cells in the buccal complex. AMC. 2012.

13. González Orta LJ, Font Rytzner A, De Nova García MJ. Research with stem cells of dental origin. Update Gac Dent Dig. 2011.22(3).

14. Huang J, Gronthos S, Shi S. Mesenchymal stem cells derived from dental tissues vs those from other sources: Their biology and regenerative medicine. J Dental Res. 2009;88(9):792-806.

15. American Association of Endodontists. Regenerative endodontics: considerations for regenerative procedures. 2014.

16. Cohenca N, Paranjpe A, Berg J. Vital pulp therapy. Dental Clin North Am. 2013;57(7):59-73.

17. Misako KI, Koichiro Iohara, Masashi M. Dental pulp stem cells and regeneration. Endodontic Topics. 2013;28(1):38-50.

18. Smith A, Scheven B, Takahashi Y, et al. Dentine as a bioactive extracellular matrix. Arch Oral Biol. 2012;57(2):109-121.

19. Jadhav G, Shah N, Logani A. Revascularization with and without plateletrich plasma in nonvital, immature, anterior teeth: a pilot clinical. $J$ Endod. 2012;38(12):1581-1587.
20. Torabinejad M, Faras H. A clinical and histological report of a tooth with an open apex treated with regenerative endodontics using platelet-rich plasma. $J$ Endod. 2012;38(6):864-868.

21. Martin G, Ricucci D, Gibbs JL, Lin LM. Histological findings of revascularized/ revitalized immature permanent molar with apical periodontitis using platelet-rich plasma. $J$ Endod. 2013;39(1):138-144.

22. Torabinejad M, Turman M. Revitalization of tooth with necrotic pulp and open apex by using platelet-rich plasma: a case report. $J$ Endod. 2011;37(2):265-268.

23. Johns DA, Vidyanath S. Revitalization of tooth with necrotic pulp and open apex by using platelet-rich plasma: a case report. $J$ Endod. 2011;37(6):743.

24. Huang FM, Yang $\mathrm{S}$, Zhao $\mathrm{JH}$, et al. Platelet-rich fibrin increases proliferation and differentiation of human dental pulp cells. $J$ Endod. 2010;36(10):1628-1632

25. Banchs F, Trope M. Revascularization of immature permanent teeth with apical periodontitis: new treatment protocol. JEndod. 2004;30(4):196-200.

26. Hoshino E, Kurihara Ando N, Sato I, et al. In-vitro antibacterial susceptibility of bacteria taken from infected root dentine to a mixture of ciprofloxacin, metronidazole and minocycline. Int Endod J. 1996;29(2):125-130.

27. Chueh LH, Huang GTJ. Immature teeth with periradicular periodontitis or abscess undergoing apexogenesis: a paradigm shift. $J$ Endod. 2006;32(12):1205-1213

28. Jung IY, Lee SJ, Hargreaves KM. Biologically based treatment of immature permanent teeth with pulpal necrosis: a case series. $J$ Endod. 2008;34(7):876-887.

29. Cotti E, Mereu M, Lusso D. Regenerative treatment of an immature, traumatized tooth with apical periodontitis: report of a case. $J$ Endod. 2008;34(5):611-616.

30. Chueh LH, Ho YC, Kuo TC. Regenerative endodontic treatment for necrotic immature permanent teeth. J Endod. 2009;35(2):160-164.

31. Cehreli ZC, Isbitiren B, Sara S. Regenerative endodontic treatment (revascularization) of immature necrotic molars medicated with calcium hydroxide: a case series. J Endod. 2011;37(9):1327-1330.

32. Iwaya S, Ikawa $M$, Kubota $M$. Revascularization of an immature permanent tooth with periradicular abscess after luxation. Dent Traumatol. 2011;27(1):55-58

33. Bose R, Nummikoski P, Hargreaves K. A Retrospective evaluation of radiographic outcomes in immature teeth with necrotic root canal systems treated with regenerative endodontic procedures. $J$ Endod. 2009;35(10):1343-1349.

34. Reynolds K, Johnson JD, Cohenca N. Pulp revascularization ofnecrotic bilateral bicuspids using a modified novel technique to eliminate potential coronal discolouration: a case report. Int Endod J. 2009;42(1):84-92.

35. Galler KM, D'Souza RN, Federlin M, et al. Dentin conditioning codetermines cell fate in regenerative endodontics. $J$ Endod. 2011;37(11):1536-1541.

36. Thomson A, Kahler B. Regenerative endodontics biologically based treatment for immature permanent teeth: a case report and review of the literature. Aust Dent J. 2010;55(4):446-452.

37. Nosrat A, Seifi A, Asgary S. Regenerative endodontic treatment (revascularization) for necrotic immature permanent molars: a review and report of two cases with a new biomaterial. $J$ Endod. 2011;37(4):562-567.

38. Nosrat SFA. Pulp regeneration in previously infected root canal space. Endodontics Topics. 2013;28(1):24-37. 